\title{
APLICAÇÃO DE ALTA PRESSÃO ISOSTÁTICA NA PRODUÇÃo DE DERIVADOS LÁCTEOS: UMA REVISÃO
}

\author{
High Isostatic Pressure Application in Dairy Products: A Review
}

Ana Carolina Nunes de Morais $^{{ }^{*}}$, Elisa Helena da Rocha Ferreira ${ }^{l}$, Amauri Rosenthal ${ }^{2}$

\section{RESUMO}

A Alta Pressão Isostática (API) tem ganhado destaque em diversos setores da indústria, inclusive o de laticínios. Esta tecnologia emergente é eficaz para garantir aos alimentos segurança microbiológica semelhante aos processos térmicos convencionais (pasteurização), com a vantagem de preservar as características sensoriais e nutricionais, oferecendo ao consumidor produtos mais próximos ao natural. O objetivo do presente estudo foi realizar uma revisão de literatura sobre a aplicação e as perspectivas da API na indústria de alimentos, principalmente no tocante à indústria de laticínios.

Palavras-chave: inovação tecnológica; processo não térmico; alta pressão isostática; segurança alimentar; laticínios.

\begin{abstract}
High Isostatic Pressure (HIP) has gained prominence in several food industry sectors, including dairy. This emerging technology is effective to ensure microbiological safety to food similarly to conventional thermal processes (pasteurization), with the advantage of maintaining favorable sensory and nutritional characteristics, providing consumers products similar to the natural. The aim of this study was to put up a literature review on the application and prospects of HIP in food industry, especially regarding the dairy industry.

Keywords: technological innovation; non thermal technology; high isostatic pressure; food safety; dairy products.

1 Universidade Federal Rural do Rio de Janeiro (UFRRJ), Instituto de Tecnologia, Departamento de Tecnologia de Alimentos, BR 467 km 7, 23890-000, Seropédica, RJ, Brasil. E-mail: nunesdemorais@ ymail.com

2 Empresa Brasileira de Pesquisa Agropecuária (EMBRAPA) Agroindústria de Alimentos.

* Autor para correspondência
\end{abstract}




\section{INTRODUÇÃO}

A produção mundial de leite e produtos lácteos tem aumentado progressivamente. $\mathrm{O}$ Brasil tem acompanhado esta tendência, e segundo dados da Food Agriculture Organization (FAO), em 2011, o país ocupava a quinta posição no ranking dos principais produtores mundiais de leite, superado somente por Índia, Estados Unidos, China e Paquistão (FAO, 2013a). O leite está entre os seis produtos agropecuários mais importantes da economia brasileira e sua produção concentra-se principalmente em pequenas propriedades rurais (BARBOSA et al., 2012).

O consumo per capita de leite e derivados também tem aumentado e a demanda por tais produtos nos países em desenvolvimento tem crescido com o aumento da renda média da população, urbanização e modificações dos hábitos alimentares (FAO, 2013b). Com a produção e o consumo de leite mais constante, estima-se que a indústria de laticínios se beneficie progressivamente. Atualmente, existem no país mais de 1500 estabelecimentos de captação de leite e produção de derivados lácteos. Dentre os principais derivados incluem-se queijos, doces, manteigas, iogurtes e bebidas lácteas (SIQUEIRA et al., 2010).

As principais modificações sofridas pela cadeia de laticínios no Brasil foram decorrentes da granelização e do aumento da produção. A pasteurização e o tratamento UHT são as principais tecnologias utilizadas para assegurar que o leite e seus derivados cheguem microbiologicamente seguros e estáveis até o consumidor. No entanto, por fazerem uso do calor, esses processos reduzem aspectos de qualidade sensorial e nutricional do alimento, o que pode ser atribuído à destruição de vitaminas, formação de sabor de cozido e de off-flavours e modificações na cor, relacionadas à reação de Maillard e à precipitação de proteínas (BILBAO-SÁINZ et al., 2009; OLIVEIRA; ANJOS, 2012).
A indústria de alimentos tem procurado suprir os anseios do consumidor por produtos mais saudáveis, frescos, palatáveis, livres de aditivos e microbiologicamente seguros investindo em tecnologias emergentes e mais "limpas", que não utilizam calor ou que o apliquem de forma moderada. A Alta Pressão Isostática (API), também conhecida como Alta Pressão Hidrostática, é uma das principais tecnologias emergentes capazes de substituir os processos térmicos convencionais de forma ecologicamente sustentável, uma vez que permite a redução do consumo de energia e dos custos de operação. Os compostos de baixo peso molecular, responsáveis pelas características sensoriais e nutricionais dos alimentos, não são afetados pela pressurização, porém os componentes de alto peso molecular, como as proteínas, responsáveis pela estrutura e funcionalidade são mais suscetíveis a alterações pela aplicação da API (TOEPFL et al., 2006; YALDAGARD et al., 2008; CHAWLA et al., 2011).

Assim, a API tem sido considerada um método capaz de modificar a estrutura proteica, promover a inativação ou ativação enzimática e evitar a utilização ou formação de compostos químicos indesejáveis. Para a indústria de laticínios, estas características são fundamentais, pois podem favorecer o tratamento do leite ou a obtenção de derivados com características sensoriais e nutricionais diferenciadas (TRUJILLO et al., 2002; WANG et al., 2013). O objetivo do presente estudo é realizar uma revisão de literatura sobre a aplicação e as perspectivas da API na indústria de alimentos, principalmente no que diz respeito à indústria de laticínios.

\section{REFERENCIAL TEÓRICO}

\section{Alta Pressão Isostática: breve histórico, princípios e recentes avanços}

As primeiras pesquisas referentes à preservação de alimentos por API se deram 
no final do século XIX, com o pioneiro estudo de Bert Hite, que relatou os efeitos da pressurização na vida de prateleira do leite (HITE, 1899). Entretanto, foi somente um século depois, no Japão, após 1990, que surgiram os primeiros alimentos processados por API e destinados ao comércio (TRUJILLO et al., 2002).

A API segue o princípio de Pascal (ou isostático), em que a pressão é transmitida uniformemente e quase que instantaneamente por todo o alimento, independente de sua massa, tamanho ou composição. Sob pressão as biomoléculas obedecem ao princípio de Le Chatelier que favorece reações químicas que promovem a diminuição de volume. A condição adiabática do processo faz com que, independentemente do tamanho e do formato do alimento, exista pouca variação de temperatura com o aumento da pressão (a temperatura aumenta aproximadamente $3{ }^{\circ} \mathrm{C}$, por $100 \mathrm{MPa}$, dependendo da constituição do alimento), o que previne que o alimento seja substancialmente deformado ou aquecido (CHAWLA et al., 2011).

A conservação de alimentos utilizando API consiste em submeter alimentos líquidos ou sólidos a pressões entre $100 \mathrm{MPa}$ e 800 MPa por um tempo de processo determinado, associada ou não com certa elevação da temperatura, podendo o alimento estar ou não embalado (FDA, 2011). Alguns autores relatam que a pressão aplicada no processo pode variar de 100 a $1000 \mathrm{MPa}$, ou além deste valor, dependendo do objetivo do método, da capacidade do equipamento e do microrganismo que se deseja inativar (CHEFTEL, 1995; SMELT, 1998).

O sistema completo de API deve ser composto por recipiente de pressão e seu fechamento, sistema de geração e intensificação de pressão, dispositivo para controle de temperatura e demais variáveis de processo e sistema operacional (HOOVER, 1993). A pressurização acontece a partir da inserção de alimentos acondicionados em embalagens flexíveis em uma câmara de compressão, que é fechada e preenchida com o meio de transmissão de pressão (geralmente a água), expulsando todo o ar. A pressurização é iniciada e ao término do ciclo, a câmara é despressurizada (CHEFTEL, 1995; FARKAS; HOOVER, 2000).

A pressão pode ser transmitida através de dois métodos. No método direto, o meio de transmissão de pressão contido na câmara é diretamente pressurizado por um pistão e gera pressão rapidamente. No entanto, uma limitação deste método é a necessidade de vedações eficientes entre o recipiente de pressão e o pistão, fazendo com que seja restrito a equipamentos de pequeno volume, geralmente utilizados em laboratórios e plantas piloto. No método indireto, utiliza-se um intensificador de pressão para bombear o meio de transmissão de pressão do reservatório para o interior da câmara de pressão já fechada, sendo empregado em nível industrial devido a sua maior capacidade de alcançar níveis mais altos de pressão (SINGH; YOUSEF, 2001).

O processamento por API pode ser dividido em três categorias operacionais: batelada (descontínuo), semicontínuo e homogeneização (contínuo). O processo por batelada é o mais comum, por conta da simplicidade do equipamento e da execução da técnica. $\mathrm{O}$ alimento é embalado e pressurizado dentro da câmara de pressão, utilizando um meio líquido que transfere pressão ao produto. Há baixo risco de contaminação cruzada e mesmo de contaminação em caso de falhas operacionais. O processo semicontínuo é utilizado quando se deseja aumentar a produção do sistema por batelada e envolve a combinação de múltiplos recipientes de compressão, dispostos de forma a garantir um fluxo contínuo de pressurização e a recuperação de energia. Os processos por batelada e semicontínuo podem ser utilizados tanto para alimentos líquidos quanto para sólidos. Em contraposição, o 
processo por homogeneização (contínuo) tem sido proposto apenas para alimentos líquidos. O equipamento é composto por tubos ou recipientes de retenção que promovem um tempo de tratamento específico para o processo. Após o processamento, o alimento é acondicionado em tanques estéreis para posterior embalagem (SINGH; YOUSEF, 2001; FDA, 2011).

Atualmente, diversas empresas têm investido no desenvolvimento de equipamentos de API, em colaboração com grupos de pesquisa e a indústria de alimentos. Há diferentes tipos de equipamentos, cada qual com uma característica específica de design ou funcionalidade. Equipamentos mais tradicionais podem atingir $600 \mathrm{MPa}$, mas algumas empresas na Europa (Stansted Fluid Power ${ }^{\circledR}$ ) desenvolveram equipamentos capazes de atingir $1400 \mathrm{MPa}$, a $20-150{ }^{\circ} \mathrm{C}$, em em poucos segundos. Já a AVURE Technologies, a Hyperbaric e a Multivac oferecem equipamentos em layout horizontal ou vertical, dependendo do tipo de alimento a ser processado e do espaço disponível. Os equipamentos em escala industrial dessas empresas apresentam capacidade variável, de 35 a 320 litros na câmara de compressão, sendo esta geralmente superior a 150 litros Há também equipamentos com câmara de capacidade de 525 e 687 litros para o processamento de produtos cárneos e de pescado (BERMÚDEZ-AGUIRRE; BARBOSA-CÁNOVAS, 2011; AVURE TECHNOLOGIES, 2014; HYPERBARIC, 2014; MULTIVAC, 2014).

A tecnologia de API oferece diversas vantagens, dentre as quais (1) homogeneidade do tratamento, pois a pressão é aplicada uniformemente e ao redor de todo o alimento, (2) impacto mínimo pelo calor, (3) vida de prateleira dos produtos semelhante ou superior à dos alimentos tratados por pasteurização térmica, mantendo parâmetros de qualidade nutricional e sensorial e (4) pequena quantidade de energia necessária para comprimir um sólido ou líquido a $500 \mathrm{MPa}$, em comparação com o aquecimento a $100{ }^{\circ} \mathrm{C}$. Assim, a tecnologia de API está progressivamente ganhando aplicabilidade, principalmente para alimentos que apresentam alta acidez. Além dos benefícios para o consumidor e para o meio ambiente, devido à necessidade reduzida de energia, a metodologia é aplicável para alimentos embalados, tornando desnecessários e obsoletos os esforços para prevenir recontaminação ou o uso de processos de enchimento assépticos (PEREIRA; VICENTE, 2010).

O interesse na API deriva de sua capacidade de preservar atributos originais de cor, sabor, odor, qualidade e conteúdo nutricional. A pressurização é capaz de alterar a estrutura de moléculas de alto peso molecular, como proteínas e carboidratos. Moléculas menores, como compostos voláteis, pigmentos, vitaminas e outros compostos relacionados a características sensoriais, nutricionais e de saúde são menos afetadas. As modificações químicas em alimentos tratados por esta tecnologia são mínimas, porque durante o processo as ligações covalentes não são afetadas. Assim, o método é capaz de fornecer produtos com características sensoriais muito próximas às do alimento fresco, sem a adição de substâncias conservantes (aditivos), além de promover injúria celular a bactérias em alimentos crus, estendendo a vida de prateleira dos produtos e transformando favoravelmente características de textura e outros atributos desejáveis, como digestibilidade (CHAWLA, 2011).

Nos Estados Unidos, o U.S. National Advisory Committee on Microbiological Criteria for Foods listou a API como uma técnica de pasteurização não térmica que pode substituir pasteurização convencional. O FDA (Food and Drug Administration) e o US Department of Agriculture (USDA) aprovaram a tecnologia como um método 
capaz de ser empregado para a conservação de alimentos (WANG et al., 2013).

O método ainda apresenta entraves quanto à implementação na indústria de alimentos, por ser considerado de alto custo, principalmente ao alto capital inicial a ser investido. Atualmente, estima-se que o investimento inicial seja de 650 mil a 2,6 milhões de dólares, dependendo da capacidade do equipamento ( 55 a 425 litros). Ainda assim, espera-se que estes custos tornem-se paulatinamente mais acessíveis, como uma consequência do desenvolvimento tecnológico (SMELT, 1998; MARTÍNEZRODRÍGUEZ et al., 2012).

A API já foi apontada como um processo economicamente favorável para a produção de queijo cheddar, sendo responsável pela economia de cerca de 30 dólares/1000 kg de queijo produzido, sugerindose que o processo tenha a mesma viabilidade para outros tipos de queijos. Na Espanha, especificamente, a pressurização já foi utilizada para a conservação de queijos e outros recheios de sanduíches, com redução de custos e aumento da vida de prateleira destes produtos (SERRANO et al., 2005; MARTÍNEZ-RODRÍGUEZ et al., 2012).

O custo médio da API é de aproximadamente 0,05 a 0,5 dólares por litro ou quilograma de alimento processado. Sob condições específicas, como por exemplo, na fabricação de alimentos ready-to-eat, o custo pode alcançar 0,08 a 0,22 dólares por quilograma, o que faz com que hoje a API seja recomendável para produtos de alto valor agregado. Ainda assim, há uma crescente aplicação deste método na indústria de alimentos e, segundo estimativas, o mercado de produtos processados por API já representa aproximadamente 2 bilhões de dólares (CRUZ et al., 2010; BERMÚDEZ-AGUIRRE; BARBOSA-CÁNOVAS, 2011).

Dentre as tecnologias emergentes, a API tem apresentado maior alcance no mercado com produtos variados, dentre os quais se incluem geleias com sabor de frutas frescas, gelatinas, molhos, sucos de fruta, polpa de abacate, sobremesas prontas para consumo e presunto cozido. Entretanto, ainda não existem produtos lácteos pressurizados disponíveis comercialmente (LÓPEZ-FANDIÑO, 2006; KADAM et al., 2012). No Brasil, os primeiros produtos industriais (sucos de fruta) produzidos por API passaram a ser comercializados no ano de 2013 (NATURAL, 2013).

Embora a API seja comprovadamente capaz de garantir a preservação das características nutricionais e sensoriais dos alimentos, predizer os efeitos do tratamento exige estudo individual, devido à complexidade de composição de cada alimento e às possibilidades de mudanças e reações que podem ocorrer durante a pressurização. Por isso, diversas pesquisas têm sido conduzidas para investigar a inativação cinética de microrganismos e enzimas, a estrutura de biopolímeros (proteínas, polissacarídeos), bem como o efeito sobre os constituintes dos produtos alimentícios (sucos, laticínios, carnes, peixes, frutas e vegetais). Assim, a API mostra-se promissora não apenas por sua capacidade de preservação dos alimentos, mas também pelo seu potencial em promover efeitos nas propriedades tecnológicas funcionais de seus constituintes (FERREIRA et al., 2008).

\section{Alta Pressão Isostática e efeitos sobre produtos lácteos}

Leite e seus derivados são amplamente consumidos como alimentos saudáveis. No Brasil, a procura por produtos nutritivos, inovadores, seguros e de prática utilização, aliada à consolidação dos produtos no mercado, contribuíram para o crescimento da indústria de lácteos, principalmente de iogurtes e bebidas lácteas, fazendo com que ganhassem grande popularidade (THAMER; PENNA, 2006). 
Além de apresentarem alta aceitabilidade, as bebidas lácteas constituem-se em uma forma racional e lógica de reaproveitamento do soro de queijo, que é um dos resíduos com maior capacidade poluente na indústria. Sendo assim, produzir bebidas lácteas significa converter resíduos em produtos de alto valor agregado, evitando desperdícios nutricionais e financeiros, além de impactos ambientais relevantes, já que possui alto teor orgânico. Desta forma, percebe-se que a indústria de laticínios tem investido de forma maciça em novas tecnologias de produção que sejam capazes de gerar produtos diferenciados e com maior apelo mercadológico (SIQUEIRA et al., 2013).

Neste mesmo contexto, está o maior interesse da indústria em tecnologias inovadoras. O interesse da aplicação da API no leite e derivados tem aumentado. O processo é apontado como um método capaz de contribuir para melhorar a textura de lácteos (TSEVDOU; TAOUKIS, 2011). Em termos de tecnologia de iogurtes, a API tem apresentado resultados positivos sobre o produto final. Quando o leite é previamente pressurizado, há melhorias na qualidade final do iogurte, como menor grau de sinérese, maior firmeza e acidez titulável mais baixa do que nos produtos convencionais. Algumas das razões que explicam tais diferenças é a menor desnaturação das proteínas do soro e a maior dispersão de gordura no produto, por conta dos efeitos da pressurização. Como a API permite a obtenção de iogurtes com melhor textura e viscosidade, torna-se uma alternativa para diminuir o uso de aditivos, como estabilizantes e espessantes, que comprometem as características sensoriais deste produto (PENNA et al., 2007; BERMÚDEZ-AGUIRRE; BARBOSACÁNOVAS, 2011).

A pressurização tem sido pesquisada para aplicação em leite cru, o qual é utilizado como matéria-prima na fabricação dos laticínios, ou diretamente no produto final (TSEVDOU; TAOUKIS, 2011). O tratamento por API exerce efeitos significativos e únicos em muitos componentes do leite e, por isto, tem se mostrado um método promissor (PFLANZER et al., 2008). Exaustivos estudos têm sido conduzidos para determinar os efeitos da pressurização sobre a composição do leite e, consequentemente, sobre suas propriedades tecnológicas (HUPPERTZ et al., 2002; CONSIDINE et al., 2007; CHAWLA et al., 2011).

A API afeta de forma desigual os constituintes do leite, o que pode ter influência direta no processamento de laticínios. No que se refere à fração proteica, a pressurização causa a desintegração de micelas de caseína, em partículas de caseína de menor diâmetro e formato irregular, o que promove diminuição da turbidez, aumento da homogeneidade e viscosidade do material e alteração da funcionalidade das proteínas. A estabilidade das proteínas do leite depende dos sais em solução. O equilíbrio mineral também é influenciado pela API, pois ela favorece a solubilização do fosfato de cálcio coloidal, o que desestabiliza a micela, eleva o número de interações caseína-caseína por interações hidrofóbicas e eletrostáticas e aumenta a agregação (HUPPERTZ et al., 2006; LÓPEZFANDIÑO et al., 2006; OLIVEIRA, 2013).

A API também induz a desnaturação de proteínas do soro, sendo a $\beta$-lactoglobulina sensível a tratamentos de 100 a $200 \mathrm{MPa}$, enquanto a $\alpha$-lactoalbumina e a albumina de soro bovino (BSA) são estáveis a pressões iguais ou até superiores a $400-500 \mathrm{MPa}$. A desnaturação de proteínas do soro, associada ao desequilíbrio dos íons pode alterar ou melhorar as propriedades tecnológicas do leite, aumentando a capacidade de retenção de água, a viscosidade e a densidade do gel. Isto pode contribuir substancialmente para o processamento de iogurtes, leites fermentados e queijos. No caso dos queijos, 
especificamente, a desnaturação e a resultante incorporação de proteínas do soro ao coágulo pela API resultam em aumento do rendimento dos queijos, principalmente pela maior retenção de umidade (LÓPEZ-FANDIÑO et al., 1996; TRUJILLO et al., 2002; LÓPEZFANDIÑO, 2006; CONSIDINE et al., 2007).

A API também atua sobre a gordura do leite, com efeito dependente da magnitude da pressão e da temperatura aplicadas no processo. Em estudo conduzido por Gervilla et al. (2001), pressões superiores a $500 \mathrm{MPa}$, a $25{ }^{\circ} \mathrm{C}$ e $50{ }^{\circ} \mathrm{C}$, foram capazes de aumentar o número de glóbulos de gordura de 1 a $2 \mu \mathrm{m}$ e de diminuir glóbulos de 2 a $10 \mu \mathrm{m}$ em leite de ovelha, sem causar dano à membrana. Tal tendência da API foi inversa ao que ocorre nos processos térmicos tradicionais, que causam modificação da estrutura de membrana, facilitando a ação de lipases sobre o conteúdo de gordura e favorecendo a lipólise. Portanto, amostras pressurizadas apresentaram menor teor de ácidos graxos livres do que amostras controle. Assim, a API evita a produção de off flavours no leite e consequentemente, garante melhor qualidade dos derivados.

Com relação aos componentes responsáveis pelas características nutricionais, a API a temperaturas moderadas rompe apenas ligações químicas relativamente fracas, ao contrário dos tratamentos térmicos, que podem afetar ligações covalentes e não covalentes dos alimentos. Assim, moléculas bioativas tais como vitaminas, aminoácidos, açúcares simples e compostos responsáveis pelo sabor e odor permanecem inalterados (CHAWLA et al., 2011).

Leites e derivados têm contribuição significativa na ingestão de diversos micronutrientes, tais como vitamina A (15 - 20\%) e vitaminas do complexo B, como a vitamina B2 $(60-80 \%)$ e a vitamina B12 $(90 \%)$. Todas as outras vitaminas também estão presentes em quantidades variáveis (GRAULET, 2010). Sancho et al. (1999) estudaram comparativamente o efeito da API e de tratamentos térmicos convencionais sobre vitaminas hidrossolúveis (B1, B6 e C). As vitaminas B1 e B6 não foram afetadas pela pressurização, ao contrário da vitamina $\mathrm{C}$, cuja perda foi significativa, porém independente da intensidade do tratamento. Avaliando os efeitos da pressurização à temperatura ambiente no leite, Sierra et al. (2000) relataram que a API (400 $\mathrm{MPa})$ não causou perda significativa no conteúdo de vitamina B1 e B6.

Segundo Tsevdou; Taoukis (2011), a API tem sido utilizada para melhorar as características de textura de diversos produtos lácteos. Para isto, tanto o leite cru a ser utilizado como matéria-prima quanto o produto final como queijos, iogurtes e sorvetes, podem ser submetidos à pressurização. As condições gerais do processo de pressurização devem estar entre 100 a $400 \mathrm{MPa}$, entre $10^{\circ} \mathrm{C}$ e $25^{\circ} \mathrm{C}$, por um tempo de processamento entre 10 e 15 minutos. Ainda segundo os autores, uma pressurização entre 200 e $300 \mathrm{MPa}$, entre $20{ }^{\circ} \mathrm{C}$ e $25^{\circ} \mathrm{C}$, por 10 minutos, pode levar a um produto final com melhor consistência e características sensoriais aceitáveis.

Outro campo de interesse é a possibilidade de inativação de enzimas que influenciam na qualidade do leite através da API. Dentre as principais enzimas nativas, a xantino-oxidase é inativada a pressões superiores a $400 \mathrm{MPa}$, à temperatura ambiente, seguindo modelo de cinética de primeira ordem. No entanto, fosfatase alcalina, lactoperoxidase, fosfohexoseisomerase, gamaglutamiltransferase são barorresistentes, mesmo a pressões superiores a $400 \mathrm{MPa}$. A fosfatase alcalina, por exemplo, só é completamente inativada quando o leite é submetido a 800 MPa por 8 minutos, ou quando se utiliza calor no processamento. A alta estabilidade destas enzimas à pressurização torna-as inadequadas como marcadores da severidade da API (HUPPERTZ et al., 2002; LÓPEZ-FANDIÑO et al., 2006). 
Lipases naturalmente presentes no leite também são resistentes a pressões superiores a $400 \mathrm{MPa}$, enquanto proteases são ligeiramente mais suscetíveis à pressão. A plasmina, principal proteinase endógena do leite, é resistente à pressurização a 400 $\mathrm{MPa}$ por 30 minutos à temperatura ambiente, porém apresenta atividade reduzida em $86,5 \%$ quando o leite é tratado à mesma pressão, a $60{ }^{\circ} \mathrm{C}$. Outros autores já relataram a estabilidade da plasmina a pressões de até $600 \mathrm{MPa}$ e aumento da proteólise em leite tratado a pressões inferiores a $300 \mathrm{MPa}$. No geral, admite-se que o leite apresente um efeito protetor sobre a atividade enzimática (BILBAO-SÁINZ et al., 2009; LÓPEZFANDIÑO, 2006; VOIGT et al., 2012).

Além das enzimas naturalmente presentes no leite, há também enzimas proteolíticas e lipolíticas provenientes de microrganismos, sejam os propositalmente adicionados no processamento do leite ou contaminantes. Em alguns casos, a inativação enzimática é desejável para estender a vida de prateleira do produto. No entanto, na indústria de queijos, a maturação requer a proteólise para produzir características sensoriais específicas e, neste caso, a inativação enzimática não é desejável. A API pode acelerar ou retardar a proteólise em queijos dependendo da variedade ou da intensidade dos tratamentos. Pressões superiores a $400 \mathrm{MPa}$ aplicadas a queijos "azuis" resultam na redução da lipólise, devido à diminuição na contagem de bactérias lácticas ou inativação de enzimas, o que não é desejável. Por outro lado, estas reações podem ser provenientes da ação de microrganismos psicrotróficos. A capacidade da API em ampliar a vida de prateleira do leite e seus derivados se relaciona à atuação sobre tais enzimas (BERMÚDEZ-AGUIRRE; BARBOSA-CÁNOVAS, 2011; MARTÍNEZRODRÍGUEZ et al., 2012).

Em extensa revisão de literatura realizada por Martínez-Rodríguez et al. (2012), os autores relataram que queijos processados por API não apresentaram variações no teor de sólidos totais, cinzas, gorduras, proteínas, umidade e conteúdo nutricional em queijos. No entanto, a tecnologia é capaz de acelerar ou retardar o processo de maturação, pois altera a estrutura enzimática e modifica a conformação da matriz de caseína, tornando-a mais suscetível à ação de proteases ou de enzimas microbianas, além de aumentar o pH e modificar a distribuição de água de certas variedades de queijo, levando a melhores condições para a atividade enzimática. Desta forma, a API acelera a maturação de queijos, diminuindo o tempo de armazenamento e reduzindo custos na produção. Por outro lado, sob condições de pressão superiores a $400 \mathrm{MPa}$, a API foi capaz de desacelerar a maturação em queijos cheddar, o que pode ser de grande valia para o produtor, uma vez que o queijo apresentaria atributos sensoriais favoráveis por maior tempo. Os diferentes efeitos da API sobre a maturação de queijos se relacionam com a influência da pressurização sobre a proteólise e a lipólise, e são dependentes do tipo de queijo em questão, da magnitude da pressão aplicada e em que momento da maturação o tratamento é realizado.

A pressurização pode modificar a textura de queijos e, assim como para as reações enzimáticas, o efeito depende do tipo de queijo, da magnitude e do tempo de aplicação da pressão. Para queijo gouda, por exemplo, a pressurização aumentou o comportamento viscoelástico e reduziu a rigidez do produto (O’REILLY et al., 2001). Para queijo mussarela com baixo teor de umidade a API a 400 MPa por 20 minutos, provocou aumento de fluidez, da capacidade de estiramento e reduziu o tempo de fusão a $280^{\circ} \mathrm{C}$, enquanto que para este mesmo tipo de queijo com reduzido teor de gordura, o tratamento à mesma pressão, por 5 minutos não modificou tais características. Para queijo cheddar, a API a $400 \mathrm{MPa}$ não 
causou alterações na firmeza do produto, porém modificou o padrão de deformação ao longo da maturação. Pressões moderadas (200 a $300 \mathrm{MPa}$ ) aumentaram a firmeza em queijos de leite de ovelha e pressões mais altas (500 $\mathrm{MPa}$ ) causaram maior deformabilidade e menor rigidez destes queijos. Para "queso fresco", amostras pressurizadas a $400 \mathrm{MPa}$ por 20 minutos foram menos quebradiças que amostras controle, e apresentaram maior firmeza, gomosidade e mastigabilidade no primeiro dia após a pressurização, sendo este mesmo comportamento observado para queijo cheddar produzido a partir de leite pressurizado a 400 e $600 \mathrm{MPa}$ (MARTÍNEZRODRÍGUEZ et al., 2012; VOIGT et al., 2012).

Pressões em torno de 200 a $400 \mathrm{MPa}$ não apresentam efeito significativo sobre a sinérese de queijos, no entanto, quando aplicadas em torno de $600 \mathrm{MPa}$, causam a diminuição deste fenômeno, possivelmente devido à formação de uma rede de gel mais fina e à maior inclusão de proteínas do soro ao coágulo (NEEDS et al., 2000).

\section{API e a segurança microbiológica de pro- dutos lácteos}

O leite é um produto altamente perecível devido aos seus fatores intrínsecos e que deve ser submetido a tratamentos de conservação para assegurar sua segurança microbiológica e vida de prateleira estável (CHAWLA, 2011). Muitos estudos provaram que o tratamento por API entre 400 e $600 \mathrm{MPa}$ é capaz de inativar os principais microrganismos presentes no leite, sejam estes deteriorantes ou patogênicos, oferecendo um produto com a mesma qualidade do leite pasteurizado. No entanto, não é suficiente para promover a esterilização, uma vez que os esporos bacterianos são resistentes ao processo (TRUJILLO et al., 2002).

O efeito da pressurização sobre os microrganismos pode ser influenciado pelas condições do processamento (pressão, tempo, temperatura, ciclos), pela matriz do alimento (fatores intrínsecos) e pelo estado fisiológico dos microrganismos. Células em crescimento exponencial são mais suscetíveis à pressão do que aquelas em fase estacionária, e microrganismos Gram positivos tendem a ser mais resistentes à pressão que os Gram negativos havendo, no entanto, uma variação considerável na resistência entre estirpes da mesma espécie (SMELT, 1998).

A membrana celular é a primeira estrutura a apresentar comprometimento com o aumento da pressão. A API provoca mudanças na organização molecular da dupla camada de ácidos fosfatídicos, além de promover a desnaturação parcial ou irreversível de proteínas e enzimas, propiciando a alteração da permeabilidade à passagem de íons. A membrana perde sua funcionalidade, bem como sua integridade estrutural. As modificações na morfologia celular afetam a absorção de nutrientes e as vias metabólicas de eliminação de resíduos. O colapso da membrana favorece ainda a perda de proteínas e RNA para o meio extracelular. Com relação ao material genético, a API inibe reações enzimáticas envolvidas na replicação e transcrição do DNA microbiano (RENDUELES et al., 2011; HUANG et al., 2014).

Segundo Pflanzer et al. (2008), dentre os microrganismos deteriorantes do leite e derivados, bactérias do gênero Pseudomonas spp. são consideradas as mais importantes. Embora não sejam causadoras de Doenças Transmitidas por Alimentos (DTAs), têm importância por serem psicrotróficas, ou seja, por sobreviverem à temperatura de refrigeração e assim causar a deterioração de lácteos refrigerados. Com relação aos patogênicos, os principais causadores de DTAs relacionados aos lácteos são Staphylococcus aureus, Yersinia enterocolitica, Salmonella spp., Escherichia coli e Listeria spp.. Por este motivo, ao longo dos últimos anos mui- 
tos estudos têm avaliado a inativação de microrganismos patogênicos e deteriorantes (naturalmente presentes ou inoculados no leite) pela API (TRUJILLO et al., 2002).

Segundo Trujillo et al. (2002), em leite caprino tratado a $250 \mathrm{MPa}, 25{ }^{\circ} \mathrm{C}$, P. fluorescens apresentou uma cinética de destruição superior a Escherichia coli, Listeria innocua, Lactobacillus helveticus e Staphylococcus aureus. A suscetibilidade da bactéria à pressão foi maior quando o experimento foi realizado à temperatura de $4{ }^{\circ} \mathrm{C}$ do que quando realizado à temperatura ambiente $\left(25^{\circ} \mathrm{C}\right)$.

Staphylococcus aureus são microrganismos causadores de DTAs através da produção de toxinas e estão entre as principais bactérias causadoras de mastite em animais de produção. Bozoglu et al. (2004) relataram uma inativação maior que 7 ciclos logarítmicos quando leite UHT foi tratado a $350 \mathrm{MPa}$, $45{ }^{\circ} \mathrm{C}$ por $10 \mathrm{~min}$, tendo sido encontradas células viáveis apenas após 15 dias de estocagem a $4{ }^{\circ} \mathrm{C}$. Huppertz et al. (2006) avaliaram o efeito da API sobre $S$. aureus NCTC 10652 e encontraram inativação de 5 ciclos logarítmicos quando leite UHT foi submetido à $600 \mathrm{MPa}, 20^{\circ} \mathrm{C}$ por 30 minutos. Já López-Pedemonte et al. (2007a) inocularam duas linhagens de S. aureus (CECT4013 e ATCC13565) em leite pasteurizado a ser utilizado na fabricação de queijos e os submeteram à pressurização a 300, $400 \mathrm{e}$ $500 \mathrm{MPa}, 5{ }^{\circ} \mathrm{C}$ ou $20{ }^{\circ} \mathrm{C}$ por 10 minutos. A contagem de $S$. aureus foi menor quanto maior o nível de pressão aplicado e o tempo de maturação (tempo máximo considerado foi de 30 dias), não havendo influência da temperatura. No entanto, foi possível detectar a toxina em todas as amostras de queijo contendo a linhagem ATCC 13565, antes e depois da API e 30 dias após a maturação, o que sugere que mais estudos devem ser conduzidos para detectar os efeitos da API sobre a toxina estafilocócica.

Yersinia enterocolitica é uma bac- téria psicrotrófica que também tem sido incriminada pela ocorrência de DTAs. Castellví et al. (2005) inocularam leite UHT desnatado com quatro sorotipos patogênicos de $Y$. enterocolitica e o submeteram à pressurização, concluindo que todos os sorotipos foram completamente inativados (redução de 8 ciclos logarítmicos) quando as amostras foram tratadas a $400 \mathrm{MPa}, 20{ }^{\circ} \mathrm{C}$, por 10 minutos.

As salmoneloses estão entre as principais DTAs no mundo, inclusive no Brasil, podendo estar relacionadas a diversos alimentos, dentre os quais produtos lácteos. Guan et al. (2005) demonstraram a inativação de 5 ciclos logarítmicos de Salmonella typhimurium DT 104 em leite UHT integral, utilizando $450 \mathrm{MPa}, 21^{\circ} \mathrm{C}$ por 30 minutos.

Escherichia coli é o maior indicador sanitário em produção de alimentos, e vários sorotipos podem causar infecções ou intoxicações alimentares. Dentre estes, E. coli O157:H7 tem sido relacionado a surtos graves. Huppertz et al. (2006) relataram que em leite UHT experimentalmente inoculado com $E$. coli O157:H7 NCTC 12079, tratamentos por pressurização, a $700 \mathrm{MPa}, 40{ }^{\circ} \mathrm{C}$ por 15 minutos e $200 \mathrm{MPa}, 60{ }^{\circ} \mathrm{C}$ por 15 minutos, foram capazes de reduzir a contagem de bactérias em 8 ciclos logarítmicos.

Listeria spp. é um patógeno de grande importância na indústria de laticínios, por conta de sua ampla distribuição. Pode manter-se viável inclusive em produtos lácteos mantidos sob refrigeração ou mesmo naqueles que tenham passado por etapas de processamento, e apresentem longa vida de prateleira (LÓPEZ-PEDEMONTE et al., 2007b). Segundo Huppertz et al. (2006), em leite UHT tratado por $700 \mathrm{MPa}, 20$ ${ }^{\circ} \mathrm{C}$ por 10 minutos, foi possível observar uma redução de 7,5 ciclos logarítmicos na contagem de L. monocytogenes Scott A. No entanto, a maior parte dos estudos têm avaliado os efeitos da API em queijos para 
a inativação de Listeria spp.. Em pesquisas conduzidas por Szczawiński et al. (1997) e Gallot-Lavallé (1998), a pressurização foi capaz de promover a inativação de $L$. monocytogenes em queijos obtidos de leite bovino e ovino, respectivamente, sem causar prejuízo a suas características sensoriais. Já López-Pedemonte et al. (2007b) relataram que o emprego de API associado ao aquecimento brando, tempo de maturação adequado e refrigeração foram capazes de garantir a segurança microbiológica de queijos.

Esporos são mais resistentes que células vegetativas e podem sobreviver a pressões superiores a $1000 \mathrm{MPa}$, no entanto, também podem ser estimulados a germinar quando expostos a pressões da ordem de 50 a $300 \mathrm{MPa}$. Os esporos germinados podem ser inativados pela aplicação de calor associada à pressão ou por pressões moderadas (SMELT, 1998; CHAWLA et al., 2011).

Wuytack et al. (1998) avaliaram a indução da germinação de esporos bacterianos por API e demonstraram que a inativação a $600 \mathrm{MPa}$ foi maior quando havia prétratamentos em pressões até $200 \mathrm{MPa}$, do que em pré-tratamentos com $500 \mathrm{MPa}$, sugerindo que baixas pressões ativam um sistema enzimático responsável pela germinação, o que não ocorre em altas pressões. Em termos de inativação, para Bacillus cereus o melhor tratamento encontrado propiciou redução superior a 6 ciclos logarítmicos na contagem de quatro cepas, utilizando duas fases: a primeira a $200 \mathrm{MPa} / 45^{\circ} \mathrm{C} / 10$ minutos e a segunda a $200 \mathrm{MPa} / 60{ }^{\circ} \mathrm{C}$, também por 10 min. Os resultados do tratamento combinado foi melhor que em um único tratamento, a $500 \mathrm{MPa} / 45{ }^{\circ} \mathrm{C} / 10$ minutos. Aouhadi et al. (2013) avaliaram o efeito da pressurização sobre Bacillus sporothermodurans, pelo método de superfície de resposta em água destilada e leite. Para a redução de 5 ciclos logarítmicos na contagem de esporos no leite, as condições ideais foram $495 \mathrm{MPa}, 49{ }^{\circ} \mathrm{C}$ e 30 minutos, demonstrando a eficiência da
API associada à temperatura moderada para a inativação de esporos. Um tratamento como este poderia ser utilizado na indústria de modo a garantir a esterilidade comercial de leite, uma vez que esporos de Bacillus spp. são comuns nos produtos lácteos e resistentes ao tratamento UHT.

A maior parte das pesquisas envolvendo API e leite refere-se a microrganismos patogênicos e bactérias lácticas. Poucos estudos tratam do efeito sobre fungos, principalmente no escopo de produtos lácteos. Martínez-Rodríguez et al. (2014) investigaram o efeito da tecnologia em diferentes faixas de pressão $(300,400$ e 500 $\mathrm{MPa}$ ) sobre o desenvolvimento micelial, viabilidade dos esporos e atividade lipolítica e proteolítica de Penicillium roqueforti PV-LYO 10D. Os autores demonstraram que a pressurização foi capaz de controlar o crescimento micelial, inativar esporos e modificar a atividade enzimática do fungo, o que pode ser interessante para aplicação prática, a fim de obter queijos e outros produtos com maior vida de prateleira.

É importante destacar que os estudos que envolvem a inativação de microrganismos através da API podem ser conduzidos em solução tampão, caldo nutriente ou no próprio alimento. De modo geral, a inativação em soluções tampão ou em caldo nutriente é mais eficiente, o que pode ser atribuído a um efeito baroprotetor do leite sobre os microrganismos (USAJEWICZ; NALEPA, 2006; YALDAGARD et al., 2008; AOUHADI et al., 2013), devido possivelmente ao teor de gordura, sólidos e carboidratos.

Assim, ressalta-se que à medida que a indústria investe na API como uma tecnologia substituinte ou complementar aos processos tradicionais, deve-se investir também em novos estudos que investiguem seus efeitos sobre a segurança microbiológica dos alimentos. Há certa complexidade ao considerar tal aspecto, uma vez que a barorresistência dos microrganismos não é uniforme. A apli- 
cação de condições inadequadas de pressão pode ser incapaz de impedir o desenvolvimento microbiano, resultando em falhas na segurança alimentar. Por este motivo, antes de desenvolver um produto por API, deve-se compreender as características dos microrganismos patogênicos em relação à pressão assim como seu comportamento após a aplicação da pressão (HUANG et al., 2014).

A principal função da pasteurização é garantir a segurança microbiológica do alimento com a inibição de microrganismos patogênicos, através do emprego de calor. No entanto, é necessário avaliar cuidadosamente as condições do binômio tempo-temperatura para o êxito do processo, a fim de se obter um alimento com a menor carga microbiana possível, evitando possíveis danos na qualidade por conta das altas temperaturas. A API surge como uma alternativa viável para inibir patogênicos mantendo nível de frescor típico de um processamento mínimo (HUANG et al., 2014).

\section{Aspectos sensoriais do uso da API em produtos lácteos}

Uma das principais justificativas para a utilização da API na conservação de alimentos é o fato de garantir a segurança microbiológica dos produtos, enquanto retém as características sensoriais do alimento fresco, ao contrário do que ocorre nos tratamentos térmicos convencionais. Para leites e derivados lácteos, esta prerrogativa também se aplica. Segundo García Risco et al. (2007), a pressurização do leite a $400 \mathrm{MPa}$, a 25 $60{ }^{\circ} \mathrm{C}$ por 15 minutos mantém ou melhora suas características sensoriais, o que é favorável para a obtenção de derivados lácteos diferenciados.

Para queijos, especificamente, os efeitos da API sobre as características sensoriais podem trazer benefícios econômicos para o produtor, principalmente se o tratamento for efetuado a condições moderadas e no estágio inicial da maturação (MARTÍNEZRODRÍGUEZ et al., 2012). Em estudo conduzido por Trujillo et al. (1999) com queijos provenientes de leite caprino, as características sensoriais foram semelhantes para o produto pressurizado e pasteurizado. Já para queijos duros a API não teve influência sobre os atributos sensoriais de aparência, aroma e sabor, tendo efeito positivo na coloração de queijo Gouda (SZCZAWIŃSKI et al., 1997), o que corroborou com Kolakowski et al. (1998), que obtiveram queijo Gouda pressurizado a $500 \mathrm{MPa}$ por 4 horas, com características sensoriais superiores aos produtos tradicionais (KOLAKOWSKI et al., 1998).

A análise sensorial de queijo cheddar com três meses, fabricado com leite pressurizado, não obteve bons resultados quanto à percepção da textura, o que foi atribuído ao alto teor de umidade do produto (DRAKE et al., 1997). Por outro lado, em estudo conduzido por Serrano et al. (2005), a pressurização com intensidade moderada (345 e $483 \mathrm{MPa}$ ) melhorou as propriedades visuais e táteis de queijo cheddar desfiado, tendo a amostra pressurizada apresentado no primeiro dia após o tratamento, os mesmos atributos sensoriais observados em queijos não pressurizados e maturados por 27 dias. Já para a fabricação de queijos probióticos, a aceitação de queijos pressurizados e convencionais foi semelhante (CRUZ et al., 2010).

De acordo com Martínez-Rodríguez et al. (2012), características inovadoras ou distintas na textura, aroma, sabor e aparência de queijos podem ser obtidas através do emprego da API em determinadas condições de tratamento, tornando estes produtos mais atrativos para o consumidor.

\section{Possibilidades de aplicação da API na indústria de lácteos}

Uma vez que a tecnologia de API tem se mostrado um método eficaz para a conservação e aprimoramento de alimentos, 
pesquisas têm sido realizadas na tentativa de também incorporá-la ao processo de produtivo de diferentes categorias de produtos lácteos.

$\mathrm{O}$ crescente interesse por alimentos saudáveis vem estimulando o desenvolvimento do mercado de lácteos funcionais, como os leites fermentados. Nestes produtos, a funcionalidade é atribuída a culturas probióticas e aos metabólitos produzidos durante a fermentação do leite (OLIVEIRA; SILVA, 2011). Como estes alimentos têm se tornado cada vez mais populares, é importante considerar o emprego de novas alternativas para manter sua viabilidade durante sua vida de prateleira (CRUZ et al., 2010). Jakowska et al. (2005) produziram iogurte suplementado com bactérias probióticas e o trataram por API, relatando que as culturas de Lactobacillus acidophilus e Bifidobacterium spp. mantiveram suas populações de $10^{6}$ e $10^{7} \mathrm{UFC} / g$ durante 4 semanas e armazenamento sob refrigeração.

Tsevdou; Taoukis (2011) investigaram o efeito da API sobre a cinética de inativação de Bifidobacterium spp. a pressões de 100 a 400 $\mathrm{MPa}$ e temperatura de 20 a $35^{\circ} \mathrm{C}$. Pressão e temperatura agiram sinergicamente na perda da viabilidade microbiana. $\mathrm{O}$ tratamento a $200 \mathrm{MPa}$, $20-25{ }^{\circ} \mathrm{C}$, por $10-15$ minutos, recomendado para alcançar modificações favoráveis na textura de produtos lácteos, não promoveu perda de viabilidade de Bifidobacterium spp.. Segundo os autores, a pressões mais baixas, a temperatura tem efeito significativo na viabilidade das bactérias, enquanto para pressões mais altas (400 MPa), este efeito é menor. Tratamentos mais intensos $\left(200 \mathrm{MPa}, 30-35{ }^{\circ} \mathrm{C},<30 \mathrm{~min}\right.$ ou $300 \mathrm{MPa}, 20{ }^{\circ} \mathrm{C},<10 \mathrm{~min}$ ) também foram considerados eficazes, sendo portanto a API sugerida como um caminho a ser seguido pela indústria de laticínios, por agregar três conceitos altamente relevantes para o consumidor moderno: funcionalidade, manutenção de características sensoriais e nutricionais e sustentabilidade tecnológica.
A Companhia Fonterra ${ }^{\circledR}$ possui a patente de um processo no qual a vida de prateleira de iogurtes probióticos pode ser estendida pela pressurização, que causa a inativação de microrganismos deteriorantes, sem afetar a atividade de linhagens de bactérias probióticas baroresistentes e indispensáveis para que o alimento seja considerado funcional (CARROL et al., 2004). A tendência é que à medida que os investimentos nesta tecnologia aumentem, outras indústrias possam também fazer uso da API para otimizar a produção de lácteos funcionais.

De acordo com Cruz et al. (2010), o uso da API para o tratamento de lácteos traz diversos benefícios para os produtos probióticos, dentre os quais (1) aumenta a compressão da matriz alimentar, o que protege bactérias probióticas ao longo do trato gastrintestinal do hospedeiro; (2) minimiza a perda de bactérias probióticas durante a remoção do soro e o período de coagulação, promovendo maior controle sobre o inóculo adicionado; (3) melhora a textura e viscosidade, com decréscimo da sinérese, minimizando a adição de agentes espessantes e estabilizantes; (4) estimula o crescimento de bactérias probióticas, uma vez que elas apresentam limitada atividade proteolítica; (5) permite a obtenção de diferentes atributos sensoriais, como resultado da ação das bactérias probióticas na proteólise secundária; (6) melhora as características sensoriais, pois a atividade probiótica das bactérias na proteólise pode resultar em sabores diferenciados no produto e (7) facilita o crescimento de Streptococcus thermophilus, comparativamente a Lactobacillus bulgaricus reduzindo a pós-acidificação. Sendo assim, a API pode ser considerada uma tecnologia vantajosa para a obtenção de lácteos probióticos, principalmente queijos e leites fermentados.

Não foram encontrados estudos que relatem o efeito da API sobre bebidas lácteas 
adicionadas de fibras solúveis prebióticas. A maior parte das pesquisas detém-se aos efeitos da API sobre a atividade antioxidante e a retenção de compostos fenólicos em produtos diversos. Keenan et al. (2010) submeteram smoothies de frutas à pasteurização e pressurização (450 $\mathrm{MPa}$ por 1,3 e 5 minutos) e observaram que ambos os processamentos e o tempo de estocagem afetaram a cor do produto e a capacidade antioxidante, mas que as amostras tratadas por API apresentaram menor atividade antioxidante, o que sugere que o sistema de degradação enzimático provavelmente não foi inativado. Avaliando purês de maçã enriquecidos com inclusões de prebióticos comerciais (inulina e frutoligossacarídeos) tratados por API, Keenan et al. (2011) relataram que ambos foram estáveis e estiveram presentes em quantidade suficiente para garantir efeito prebiótico durante o armazenamento (30 dias, a $4{ }^{\circ} \mathrm{C}$ ). Esta pesquisa pode servir como base para a indústria identificar o tipo de processamento e as condições ótimas para maximizar a retenção de propriedades funcionais adicionadas ou inerentes aos alimentos, inclusive os lácteos adicionados de fibras prebióticas.

A pressurização também tem sido utilizada na produção de alimentos com reduzido teor de sódio em sua composição. Ozturk et al. (2013) submeteram queijos cheddar com diferentes concentrações de sal à API e relataram que a aplicação de pressões de $400 \mathrm{MPa}$ poderiam ser úteis para melhorar as características de queijos com baixa concentração de sal. Voigt et al. (2012), também trabalhando com queijo cheddar, avaliaram os efeitos da API e da pasteurização sobre a proteólise, lipólise, textura e funcionalidade destes produtos durante a maturação. Foi observada maior proteólise e maiores níveis de ácidos graxos livres em queijos fabricados de leite tratado a $600 \mathrm{MPa}$. Queijos fabricados a partir de leite pressurizado apresentaram características de sabor favoráveis, capacidade de mistura da massa menor e coloração mais esbranquiçada. A API neste caso pôde ajudar a eliminar a contaminação microbiana e a manter características sensoriais favoráveis, sendo uma ferramenta para o desenvolvimento de queijos seguros e diferenciados, o que pode dar à indústria vantagens competitivas no mercado.

\section{CONSIDERAÇÕES FINAIS}

Dentre as principais tecnologias inovadoras aplicadas à indústria de alimentos, destaca-se a API, pois é a única capaz de oferecer ao consumidor produtos minimamente processados de diferentes categorias. Processos envolvendo produtos lácteos e API têm sido extensivamente estudados para ampliar os conhecimentos sobre os efeitos da tecnologia nos principais microrganismos deteriorantes e patogênicos e nos constituintes do leite, que é matéria-prima para uma diversidade de produtos.

No Brasil, a aplicação da API na indústria ainda é incipiente, no entanto, os investimentos nas novas tecnologias vêm aumentando progressivamente, já que as exigências do mercado consumidor por alimentos de melhor qualidade sensorial e nutricional são crescentes. Neste contexto, acredita-se que a API possa paulatinamente ser agregada à produção alimentícia, inclusive de produtos lácteos. Para isto, maior aprofundamento técnico-científico é necessário, de forma a avaliar o potencial de aplicação a alimentos demandados e aceitos pelos consumidores brasileiros, considerando a obtenção de produtos tradicionais e inovadores que possam ser produzidos com qualidade superior diferenciada através da aplicação da API.

Ainda hoje é indiscutível a relevância dos processos térmicos para a indústria 
de alimentos. A pasteurização do leite destrói microrganismos patogênicos e a maior parte dos deteriorantes, sendo, portanto, o tratatamento térmico de maior importância aplicado à indústria de lácteos. No entanto, afeta consideravelmente as características sensoriais do leite e, consequentemente, de seus derivados. A API pode ser utilizada como método de conservação alternativo, capaz de garantir a segurança microbiológica destes produtos, além de suprir a demanda do consumidor por produtos com maior frescor e produzidos a partir de uma tecnologia sustentável, sendo, portanto, promissora para o setor de laticínios.

\section{REFERÊNCIAS}

AOUHADI, C. Inactivation of Bacillus sporothermodurans LTIS 27 spores by high hydrostatic pressure and moderate heat studied by response surface methodology. LWT - Food Science and Technology, v. 50, n. 1, p. 50-56, 2013.

AVure technologies. High Pressure Equipment. 2014. Disponível em: <http://avure. com/products $>$ Acesso em: 19 jun. 2014.

BARBOSA, A. F. et al. Perfil sensorial de bebida láctea sabor maçã verde e pêssego utilizando Análise Descritiva Quantitativa. Revista do Instituto de Laticínios Cândido Tostes, v. 67, n. 386, p. 55-60, 2012.

BERMÚDEZ-AGUIRRE, D.; BARBOSACÁNOVAS, G. V. An Update on High Hydrostatic Pressure, from the Laboratory to Industrial Applications. Food Engineering Reviews, v. 3, n. 1, p. 44-61, 2011.

BILBAO-SÁINZ, C. et al. Protease stability in bovine milk under combined thermal-high hydrostatic pressure treatment. Innovative Food Science and Emerging Technologies, v. 10, n. 3, p. 314-320, 2009.

BOZOGLU, F.; ALPAS, H.; KALETUNÇ, G.
Injury recovery of foodborne pathogens in high hydrostatic pressure treated milk during storage. FEMS Immunology and Medical Microbiology, v. 40, n. 3, p. 243-247, 2004.

CARROLL, T. et al. Pressure treating food to reduce spoilage. International Patent $n$.WO 032655, 08 out. 2003, 22 abr. 2004.

CASTELLVÍ, S. L. et al. Survival and growth of Yersinia enterocolitica strains inoculated in skimmed milk treated with high hydrostatic pressure. International Journal of Food Microbiology, v. 102, n. 2, p. 337-342, 2005.

CHAWLA, R.; PATIL, G. R.; SINGH, A. K. High hydrostatic pressure technology in dairy processing: a review. Journal of Food Science and Technology, v. 48, n. 3, p. 260-268, 2011.

CHEFTEL, J. C. Review: High-pressure microbial inactivation and food preservation. Food Science and Techology International, v. 1, n. 2-3, p. 75-90, 1995.

CONSIDINE, T. et al. Interactions of milk proteins during heat and high hydrostatic pressure treatments - A Review. Innovative Food Science and Emerging Technologies, v. 8, n. 1, p. 1-23, 2007.

CRUZ, A. G. et al. High pressure processing and pulsed electric fields: potential use in probiotic dairy foods processing. Trends in Food Science and Technology, v. 21, n. 10, p. 483-493, 2010.

DRAKE, M. A. et al. High pressure treatment of milk and effects on microbiological and sensory quality of cheddar cheese. Journal of Food Science, v. 62, n. 4, p. 843-860, 1997.

FAO. Dairy production and products. Milk production. 2013a. Disponível em: <http://www. fao.org/agriculture/dairy-gateway/milk-production/ en/\#.UmRI_nDIHxQ> Acesso em: 20 out. 2013.

FAO. Dairy production and products. Milk and Milk products. 2013b. Disponível em: <http:// www.fao.org/agriculture/dairy-gateway/milk-andmilk-products/en/\#.UmRI_nDIHxQ> Acesso em: 20 out. 2013. 
FARKAS, D. F.; HOOVER, D. G. High pressure processing. Journal of Food Science, v. 65, n. 4, p. 47-64, 2000.

FOOD AND DRUG ADMINISTRATION (FDA). Kinetics of microbial inactivation for alternative food processing technologies. High pressure processing. 2011. Disponível em: $<$ http://www.fda.gov/Food/FoodScienceResearch/ SafePracticesforFoodProcesses/ucm100158.htm> Acesso em: 26 jul.2013.

FERREIRA, E. H. R.; MASSON, L. M. P.; ROSENTHAL, A. Efeito da Alta Pressão Hidrostática nos microorganismos. Boletim do Centro de Pesquisa de Processamento de Alimentos, v. 26, n. 1, p. 135-150, 2008.

GALLOT-LAVALLÉE, T. Effectiveness of high pressure treatment for destruction of Listeria monocytogenes in raw milk goat cheese. Sciences des Aliments, v. 18, n. 6, p. 647-655, 1998.

GARCIA-RISCO, M. R. et al. Micellar changes induced by high pressure. Influence in the proteolytic activity and organoleptic properties of milk. Journal of Dairy Science, v. 83, n. 10, p. 2184-2189, 2000.

GERVILLA, R. et al. High hydrostatic pressure effects on color and Milk-fat globule of ewe's milk. Journal of Food Science, v. 66, n. 6, p. 880-885, 2001.

GRAULET, B. 9 - Improving the level of vitamins in milk. In: GRIFFITHS, M.W. (Ed.). Improving the Safety and Quality of Milk. Cambridge: Woodhead Publishing. 2010. p. 229-251.

GUAN, D.; CHEN, H.; HOOVER, D. G. Inactivation of Salmonella typhimurium DT 104 in UHT whole milk by high hydrostatic pressure. International Journal of Food Microbiology, v. 104, n. 2, p. 145-152, 2005.

HIPERBARIC HIGH PRESSURE PROCESSING.

Our Equipment. 2014. Disponível em: $<$ http:// www.hiperbaric.com/en/equipment $>$ Acesso em: 23 jun. 2014.
HITE, B. H. The effect of pressure in the preservation of milk. West Virginia Agricultural Experiment Station Bulletins. v. 58, p. 15-35, 1899.

HOOVER, D. G. Pressure effects on biological systems. Food Technology, v. 47, n. 6, p. 150155, 1993.

HUANG, H. W. et al. Responses of microorganisms to high hydrostatic pressure processing. Food Control, v. 40, p. 250-259, 2014.

HUPPERTZ, T., FOX, P. F., KELLY, A. L. Effects of high pressure on constituents and properties of milk. International Dairy Journal, v. 12, n. 7, p. 561-572, 2002.

HUPPERTZ, T. H. et al. High-pressure changes induced changes in bovine milk: a review. International Journal of Dairy Technology, v. 59, n. 2, p. 59-65, 2006.

JAKOWSKA, A.; WISNIEWSKA, K.; REPS, A. Application of probiotic bacteria in production of yogurt preserved by high pressure. International Journal of High Pressure Research, v. 25, n. 1, p. 57-62, 2005.

KADAM, P. S. et al. Review on the High Pressure Technology (HPT) for Food Preservation. Journal of Food Processing and Technology, v. 3, n. 1, p. $02-05,2012$

KEENAN, D. F. et al. Effect of thermal and high hydrostatic pressure processing on antioxidant activity and colour of fruit smoothies. Innovative Food Science and Emerging Technologies, v. 11, n. 4, p. 551-556, 2010.

KEENAN, D. F. et al. Evaluation of thermal and high hydrostatic pressure processed apple purees enriched with prebiotic inclusions. Innovative Food Science and Emerging Technologies, v. 12, n. 3, p. 261-268, 2011.

KOLAKOWSKI, P., REPS, A.; BABUCHOWSKI, A. Characteristics of Pressure Ripened Cheeses. Polish Journal of Food and Nutrition Sciences, v. 7, n. 48, p. 473-483, 1998. 
LÓPEZ-PEDEMONTE, T. High hydrostatic pressure treatment applied to model cheeses made from cow's milk inoculated with Staphylococcus aureus. Food Control, v. 18, n. 5, p. 441-447, 2007 a.

LÓPEZ-PEDEMONTE, T. Reduction of counts of Listeria monocytogenes in cheese by means of high hydrostatic pressure. Food Microbiology, v. 24, n. 1, p. 59-66, 2007 b.

LÓPEZ-FANDIÑO, R. High pressure-induced changes in milk proteins and possible applications in dairy technology. International Dairy Journal, v. 16, n. 10, p. 1119-1131, 2006.

LÓPEZ-FANDIÑO, R. et al. The Effects of High Pressure on Whey Protein Denaturation and Cheese-Making Properties of Raw Milk. Journal of Dairy Science, v. 79, n. 6, p. 929-936, 1996.

MARTÍNEZ-RODRÍGUEZ, Y. et al. Effect of high hydrostatic pressure on mycelial development, spore viability and enzyme activity of Penicillium Roqueforti. International Journal of Food Microbiology, v. 168-169, p .42-46, 2014.

MARTÍNEZ-RODRÍGUEZ, Y. et al. High Hydrostatic Pressure Processing of Cheese. Comprehensive Reviews in Food Science and Food Safety, v. 11, n. 4, p. 399-416, 2012.

MULTIVAC BETTER PACKAGING. HPP: High Pressure Preservation. 2014. Disponível em: <http://www.multivac.com.au/our-products/ hpp-high-pressure-preservation.html $>$ Acesso em: 23 jun. 2014.

NATURAL One lança novos sabores. Frigocenter. Rio de Janeiro, 27 de junho de 2013. Disponível em: <http://www.distribuidordealimentos.com/ fornecedores/natural-one-lanca-novos-sabores $>$ Acesso em: 17 nov. 2013.

NEEDS, E.C. et al. High-pressure Treatment of Milk: Effects on Casein Micelle Structure and on Enzymic Coagulation. Journal of Dairy Research, v. 67, n. 1, p. 31-42, 2000.

OLIVEIRA, C. P.; SILVA, J. A. Leite fermentado probiótico e suas implicações na saúde. Revista Verde de Agroecologia e Desenvolvimento Sustentável. v. 6, n. 3, p. 25-31, 2011.

OLIVEIRA, M. M. Avaliação de leite fermentado probiótico preparado com leite submetido à alta pressão dinâmica. 2013. 123 f. Dissertação (Mestrado em Tecnologia de Alimentos) - Universidade Estadual de Campinas, Campinas, 2013.

OLIVEIRA, P. H. B.; ANJOS, V. C. Efeitos do tratamento do leite por radiação ultravioleta (UV) em comparação à pasteurização. Revista do Instituto de Laticínios Cândido Tostes, v. 67, n. 388, p. 81-82, 2012.

O'REILLY, C. E. et al. High pressure treatment: applications in cheese manufacture and ripening. Trends in Food Science \& Technology, v. 12, n. 2, p. 51-59, 2001.

OZTURK, M. et al. The influence of high hydrostatic pressure on regular, reduced, low and no salt added Cheddar cheese. International Dairy Journal, v. 33, n. 2, p. 175-183, 2013.

PENNA, A. L. B. et al. High hydrostatic pressure processing on microstructure of probiotic low-fat yogurt. Food Research International, v. 40, n. 4, p. 510-519, 2007.

PEREIRA, R. N.; VICENTE, A. A. Environmental impact of novel thermal and non-thermal technologies in food processing. Food Research International, v. 43, n. 7, p. 1936-194, 2010.

PFLANZER, S. B. et al. Efeito do processamento por alta pressão hidrostática nas características físico-químicas, microbiológicas e nutricionais do leite. Brazilian Journal of Food Technology, v. 11, n. 4, p. 241-251, 2008

RENDUELES, E. et al. Microbiological food safety assessment of high hydrostatic pressure processing: A review. LWT - Food Science and Technology, v. 44, n. 5, p. 1251-1260, 2011.

SANCHO, F. et al. Effect of ultra-high hydrostatic pressure on hydrosoluble vitamins. Journal of Food Engineering, v. 39, n. 3, p. 247-253, 1999. 
SERRANO, J. Moderately High Hydrostatic Pressure Processing to Reduce Production Costs of Shredded Cheese: Microstructure, Texture, and Sensory Properties of Shredded Milled Curd Cheddar. Journal of Food Science, v. 70, n. 4, p. 286-293, 2005.

SIERRA, I. et al. Effect of high pressure on the vitamin B1 and B6 content of milk. Milchwissenschaft, v. 55, n. 7, p. 365-367, 2000.

SINGH, R. P.; YOUSEF, A. E. Technical Elements of New and Emerging Non-Thermal Food Technologies. 2001. Disponível em $<$ http://scholar. google.com.br/acholar_url?hl=pt-BR\&q=http:// www.worddocx.com/12051/co578.doc\&sa=X\&s cisig=AAGBfm2OYENq7yU8YRgtAnK7ktB7Z MtnhA\&oi=scholarr\&ei $=$ N-kU-H0CLXJsQSH tIDICQ\&ved=0CBsQgAMoADAA> Acesso em: 13 jun. 2014.

SIQUEIRA, A. M. O. et al. Bebidas lácteas com soro de queijo e frutas. Ciência Rural, v. 43, n. 9, p. 1693-1700, 2013.

SIQUEIRA, K. B et al. O mercado lácteo brasileiro no contexto mundial. 2010. Disponível em <http://www.infoteca.cnptia.embrapa.br/ bitstream/doc/886169/1/CT104Kennya.pdf> Acesso em: 15 jul. 2013.

SMELT, J. P. P. M. Recent advances in the microbiology of high pressure processing. Trends in Food Science and Technology, v. 9, n. 4, p. 152-158, 1998.

SZCZAWIŃSKI, J. et al. Effect of high pressure on survival of Listeria monocytogenes in ripened, sliced cheeses at ambient temperature. In: HEREMANS, K. (Ed.) High Pressure Research in the Biosciences and Biotechnology. Leuven: University Press. 1997. p. 295-298.

THAMER, K. G.; PENNA, A. L. B. Caracterização de bebidas lácteas funcionais fermentadas por probióticos e acrescidas de prebiótico. Ciência e Tecnologia de Alimentos, v. 26, n. 3, p. 589-595, jul.-set. 2006.

TOEPFL, S. et al. Review: Potential of High Hydrostatic Pressure and Pulsed Electric Fields for Energy Efficient and Environmentally Friendly Food Processing. Food Reviews International, v. 22, n. 4, p. 405-423, 2006.

TRUJILLO, A. J. et al. Applications of high hydrostatic pressure on milk and dairy products: a review. Innovative Food Sciences and Emerging Technologies, v. 3, n. 4, p. 295-307, 2002.

TRUJILLO, A. J. et al. Influence of pressurisation on goat milk and cheese composition and yield. Milchwissenschaft, v. 54, n. 4, p. $197-$ 199, 1999.

TSEVDOU, M. S.; TAOUKIS, P. S. Effect of nonthermal processing by High Hydrostatic Pressure on the survival of probiotic microorganisms: Study on Bifidobacteria spp. Anaerobe, v. 17, n. 6, p. 456-458, 2011.

USAJEWICZ, I.; NALEPA, B. Survival of E. coli O157:H7 in milk exposed to high Temperatures and high pressure. Food Technology and Biotechnology, v. 44, n. 1, p. 33-39, 2006.

VOIGT, D. D. et al. Effect of high-pressure treatment of milk for cheese manufacture on proteolysis, lipolysis, texture and functionality of Cheddar cheese during ripening. Innovative Food Science and Emerging Technologies, v. 13, p. 23-30, 2012.

WANG, C. Y. et al. The relationship between inactivation and morphologic damage of Salmonella enterica treated by high hydrostatic pressure. Food Research International, v. 54, n. 2, p. 1482-87, 2013.

WUYTACK, E. Y.; BOVEN, S.; MICHIELS, C. W. Comparative study of pressure-induced germination of Bacillus subtilis spores at low and high pressures. Applied and Environmental Microbiology, v. 64, n. 9, p. 3220-3224, 1998.

YALDAGARD, M.; MORTAZAVI, S. A.; TABATABAIE, F. The principles of ultra high pressure technology and its application in food processing/preservation: A review of microbiological and quality aspects African Journal of Biotechnology, v. 7, n. 16, p. 27392767, 2008. 